\title{
HIV positive status disclosure and associated factors among HIV positive adults in Axum health facilities, Tigray, Northern Ethiopia
}

\author{
Haileselassie Berhane Alema ${ }^{1, ~ *, ~ W o r k u ~ A w o k e ~ Y a l e w ~}{ }^{2}$, Melkamu Bedimo Beyene ${ }^{2}$, \\ Meresa Gebremedhin Woldu ${ }^{1}$ \\ ${ }^{1}$ Department of Public Health, College of Health Science, Aksum University, Axum, Ethiopia \\ ${ }^{2}$ Department of Public Health, College of Medicine and Health Science, Bahir Dar University, Bahir Dar, Ethiopia
}

\section{Email address:}

haileselasieb@yahoo.com (H. B. Alema),workuawo@yahoo.com (W. A. Yalew), melkamubb@gmail.com (M. B. Beyene), mere2010ec@yahoo.com (M. G. Woldu)

\section{To cite this article:}

Haileselassie Berhane Alema, Worku Awoke Yalew, Melkamu Bedimo Beyene, Meresa Gebremedhin Woldu. HIV Positive Status Disclosure and Associated Factors among HIV Positive Adults in Axum Health Facilities, Tigray, Northern Ethiopia. Science Journal of Public Health. Vol. 3, No. 1, 2015, pp. 61-66. doi: 10.11648/j.sjph.20150301.21

\begin{abstract}
Background: Disclosure of HIV positive status to sexual partners, friends or relatives is a main tool for prevention and care strategies. Significant proportions of HIV positive adults never disclose their HIV positive status. Identifying factors associated with disclosure is necessary to freely disclose of HIV positive status result to their sexual partners, parents and friends to achieve a goal 'zero new infection.' Objective: This study was aimed to assess the HIV positive status disclosure and associated factors among HIV positive adults attending in Axum health facilities, Northern Ethiopia. Methods: Institutional based cross-sectional study was conducted from July - August, 2013 in Axum St. Marry hospital and Axum health center. After verbal consent was obtained data were collected by trained counselors and ART nurses using pre-tested structured questionnaire. Data were entered into SPSS version 16 databases. Bivariate and multivariable logistic regression models were used to identify associated factors for disclosure of HIV positive status at $95 \%$ confidence intervals and p-value of 0.05 . Results: A total of 361 respondents were participated in the study of which gives $99.7 \%$ of response rate. The majority $(80.1 \%)$ disclosed their HIV positive result to at least one person and among currently have sexual partner, $81.2 \%$ disclosed to their current sexual partner. marital status of the respondents, [(AOR $=3.70 ; 95 \% \mathrm{CI}, 1.206-11.39)]$ knowledge of partner's HIV status [(AOR=3.43; 95\% CI, 1.02- 11.5)] and member of Anti- HIV/AIDS association [(AOR $=4.81 ; 95 \% \mathrm{CI}, 1.01-23.05)$ ] had significant association with disclosure of HIV positive status. Conclusion: The rate of HIV positive status disclosure among HIV positive adults still continued to be low. Marital status of respondents, knowledge of partners HIV status, and a member of Anti- HIV/AIDS association were identified as predictors of HIV positive status disclosure.
\end{abstract}

Keywords: HIV Positive Status Disclosure, HIV Positive Adults, Axum Health Facilities

\section{Introduction}

Globally, an estimated 35.3 million (32.2-38.8) million people were living with immune deficiency virus (HIV) in 2012. Despite the number of people newly infected continues to fall, the number of people living with HIV increased from previous years as more people are receiving the life saving antiretroviral therapy (ART). Sub-Saharan Africa remains most severely affected, with nearly 1 in every 20 adults (4.9\%) living with HIV and accounting for $69 \%$ of the people living with HIV worldwide [1].
In Ethiopia according to the Single Point Estimate, the adult HIV prevalence was estimated at $2.4 \%$ in Ethiopian Fiscal Year (EFY) 2003 (1.9\% among males and 2.9\% among females). Urban and rural HIV prevalence rates were estimated at $7.7 \%$ and $0.9 \%$ respectively. The total number of HIV-positive people was estimated at 1,216,908 out of them 397,818 were eligible for ART [2].

The rates of disclosure in studies from developing countries were notably lower than rates reported from the 
developed world. The rates ranged from $16.7 \%$ to $86 \%$. Among the studies that reported the average rate of disclosure to current sexual partner was $49 \%$, considerably less than the average rate (79\%) reported from studies conducted in developed countries [3].

Disclosing one's HIV status to a sexual partner means talking honestly about sexual orientation, possible drug use, and results of test. These are often taboo subjects that are difficult to talk about openly and honestly in most societies of developing countries [4].

Researches done at different times and various setting on the issue of HIV positive status disclosure to sexual partner have revealed that significant proportion of People living with HIV/AIDS (PHAs) do not disclose their sero - status and also ignorant of their sexual partners s status $[6,9,16,18]$. Thus, people continue to be infected from their partners with new type of HIV strain and disregard initiating ART. Even they are on ART may have negative effect on adhering to the treatment, condom use and Prevention of mother to child transmission (PMTCT). Despite this tangible fact, risky sex without disclosure of HIV status is common among people with HIV. The control of HIV infection depends on the success of strategies to prevent new infections and treat currently infected individuals. Hence, investigating into this crucial issue and analyzing the possible factors that could affect disclosure is vital to salvaging Ethiopia from this catastrophic pandemic disease. And will help explore relevant information that decision makers and managers will address the problem and in turn will contribute a lot in achieving a goal "zero new infection".

\section{Methods}

\subsection{Study Setting}

Institutional based cross-sectional quantitative study was conducted from August to September 2013 in Axum governmental health facilities (Axum General St. Marry hospital and Axum health center). These health facilities serve for more than 1.2 million people. Currently above 3558 People living with HIV/AIDS (PHAs) are utilizing in the hospital routine services with 2560 Pre ART and 998 ART care. The Axum health center also provides a service for 156 pre ART \& 142 ART [22].

\subsection{Sample Size and Sampling Techniques}

Sample size was determined by using a single population proportion formula, which considers the proportion of HIV positive status result disclosure to sexual partner is $69 \%$ [9], with marginal error of $5 \%$ at $95 \%$ confidence interval. Then by adding $10 \%$ non response rate, the final sample size was calculated to be 362 . Systematic random sampling procedure was used to select eligible participants from each ART unites. Every " $5^{\text {th }}$ " HIV positive adults who come for the ART follow-up was selected. Hence, every $5^{\text {th }}$ individuals who came to receive pre ART or ART service were selected for the interview until the required sample size was obtained.

\subsection{Data Collection and Analysis}

Data were collected by structured and pre-tested questionnaire which is adopted after reviewing relevant literatures according to objective of the research. The questionnaire was prepared in English first then translated into local language (Tigregna) and back to English to assure its consistency.

Data were collected by trained ART and counseling nurses after three days training session was given; this mainly dealt with the purpose of the study, handling ethical issues during data collection, and the method of data collection using the structured questionnaires. Data were entered in to SPSS version 16 statistical software for analysis. Descriptive statistics were used to determine the magnitude of HIV positive status disclosure and reasons to disclosing their HIV positive status. Odds ratios at $95 \%$ confidence intervals and P- value 0.05 were used to determine the significance and degree of association between dependent and independent variables. Multiple logistic regression analysis was carried out to see independent effect of each variable on the outcome.

\subsection{Operational Definitions}

HIV positive status disclosure;- The act of informing HIV positive status to any one (sexual partner, parents, families or friends).

Sexual partner; - Is a person with whom one engages in sex acts. They may be regular partner or not.

Regular sexual partner;- Is a sexual partner who lives with that partner in one home or have regular partnership with him/her.

Non-regular sexual partner; - Is a sexual partner who is not married to and never lived with that partner.

Positive outcome of disclosure; - Are those facilitating encourage to disclose HIV positive status.

Negative outcomes of disclosure; - Are those make to conceal HIV positive status like stigma and rejection, divorce, economic dependence.

\section{Results}

A total of $361 \mathrm{HIV}$ positive Adults were interviewed and the response rate was $99.7 \%$. More than half $(57 \%)$ of the respondents were female. Majority of the respondents were Orthodox Christian 316 (87.5\%) and great majority 352 $(97.5 \%)$ of them were Tigre in Ethnic group. The age of respondents ranged from 19 to 67 years with mean (SD) age of $36( \pm 8.97)$ years. Three hundred twenty eight $(90.9 \%)$ of them were urban residence (Table 1).

One hundred eighty six $(51.5 \%)$ of the respondents had sexual partners currently among them 144 (39.9) had regular sexual partner whereas, $36(10 \%)$ had non-regular partner. The mean (SD) duration of relationship with sexual partner was $10.13(8.01 \%)$ years. Regarding the knowledge of partners HIV status $163(87.6 \%)$ of the respondents knew their partner's status, among these $133(71.5 \%)$ said that their partner's were HIV positive, 30 (16.1\%) of them were negative and 23(12.4\%) 
didn't know their partner's HIV status.

Table 1. Socio-demographic characteristics of respondents (N=361) among HIV positive adults in Axum health facilities, Tigray, Ethiopia, August 2013.

\begin{tabular}{|c|c|c|c|}
\hline Variables & Categories & Frequency & Percent \\
\hline \multirow[t]{3}{*}{ Sex } & Male & 153 & 42.4 \\
\hline & Female & 208 & 57.6 \\
\hline & Orthodox & 316 & 87.5 \\
\hline \multirow[t]{3}{*}{ Religious status } & Muslim & 39 & 10.8 \\
\hline & Protestant & 6 & 1.7 \\
\hline & Unable to read and write & 104 & 28.8 \\
\hline \multirow{3}{*}{ Educational status of respondents } & Primary & 162 & 44.9 \\
\hline & Secondary & 66 & 18.3 \\
\hline & Higher education & 29 & 8.0 \\
\hline \multirow{2}{*}{ Ethnic group of respondents } & Tigre & 352 & 97.5 \\
\hline & Amara & 9 & 2.5 \\
\hline \multirow{2}{*}{ Residence of respondents } & Urban & 328 & 90.9 \\
\hline & Rural & 33 & 9.1 \\
\hline \multirow{4}{*}{ Marital status of respondents } & Single & 51 & 14.1 \\
\hline & Married & 177 & 49.0 \\
\hline & Divorced & 83 & 23.0 \\
\hline & Widowed & 50 & 13.9 \\
\hline
\end{tabular}

Table 2. Health care service related factors for HIV positive status disclosure among HIV positive adults in Axum health facilities, Tigray, Ethiopia 2013 $(N=361)$.

\begin{tabular}{llll}
\hline Variables & Categories & Frequency & Percent \\
\hline Willingly HIV sero status & Yes & 351 & 97.2 \\
done & No & 10 & 2.8 \\
Center of HIV sero status test & VCT & 130 & 36 \\
done & PICT & 231 & 64 \\
ART medication started & Yes & 322 & 89.2 \\
& No & 39 & 10.8 \\
Gets regular counseling & Yes & 358 & 99.2 \\
& No & 3 & 0.8 \\
Membership of HIV/AIDS & Yes & 116 & 32.1 \\
association & No & 245 & 67.9 \\
Substance use & Yes & 35 & 9.7 \\
& No & 326 & 90.3 \\
\hline
\end{tabular}

Among the 361 subjects interviewed, the majority $351(97.2 \%)$ did their HIV sero test willingly and two hundred $(55.4 \%)$ of their tests were done at provider initiative counseling and testing (PICT) center. About $68 \%$ of the participants were not member of anti- HIV/AIDS associations (Table 2).

Among the 361 participants, $289(80.1 \%)$ of them disclosed their HIV positive status to somebody; while $151(41.8 \%)$ disclosed to their sexual partner and $127(35.2 \%)$ disclosed to parents (figure 1).

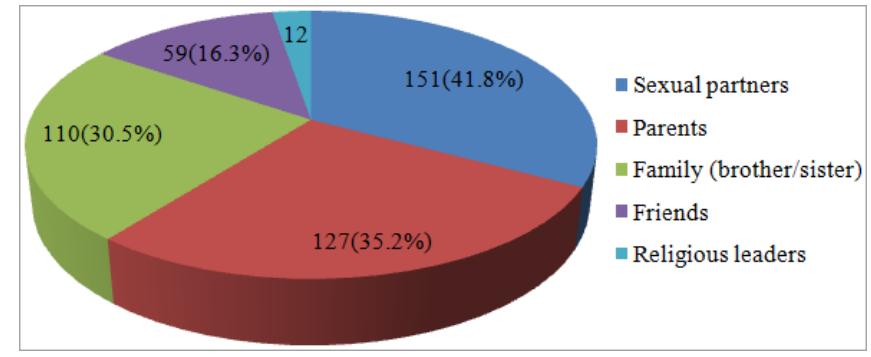

Figure 1. HIV positive test result disclosure among HIV positive adults $(N=$ 361) in Axum health facilities, Tigray, Ethiopia 2013. Multiple responses is possible

Out of 289 respondents who disclosed their HIV positive status; 202 (67\%) disclosed within one month, 39 (13.4\%) disclosed between 1 and 6 months and $48(16.6 \%)$ disclosed after 6 months of being notified their HIV positive result.

Reasons for non-disclosure among those respondents who did not disclose their HIV positive results to their partner/parents/family $(\mathrm{n}=72)$ were "fear of stigma and rejection" 68 (94.4\%), "fear of breach of confidentiality" 44 $(61.1 \%)$, "fear of shaming to family" 33 (45.8\%), "fear of divorce/ separation" 5 (6.9\%), "fear of accusation of infidelity" 5 (6.9\%), and other reasons presented in figure 2. 


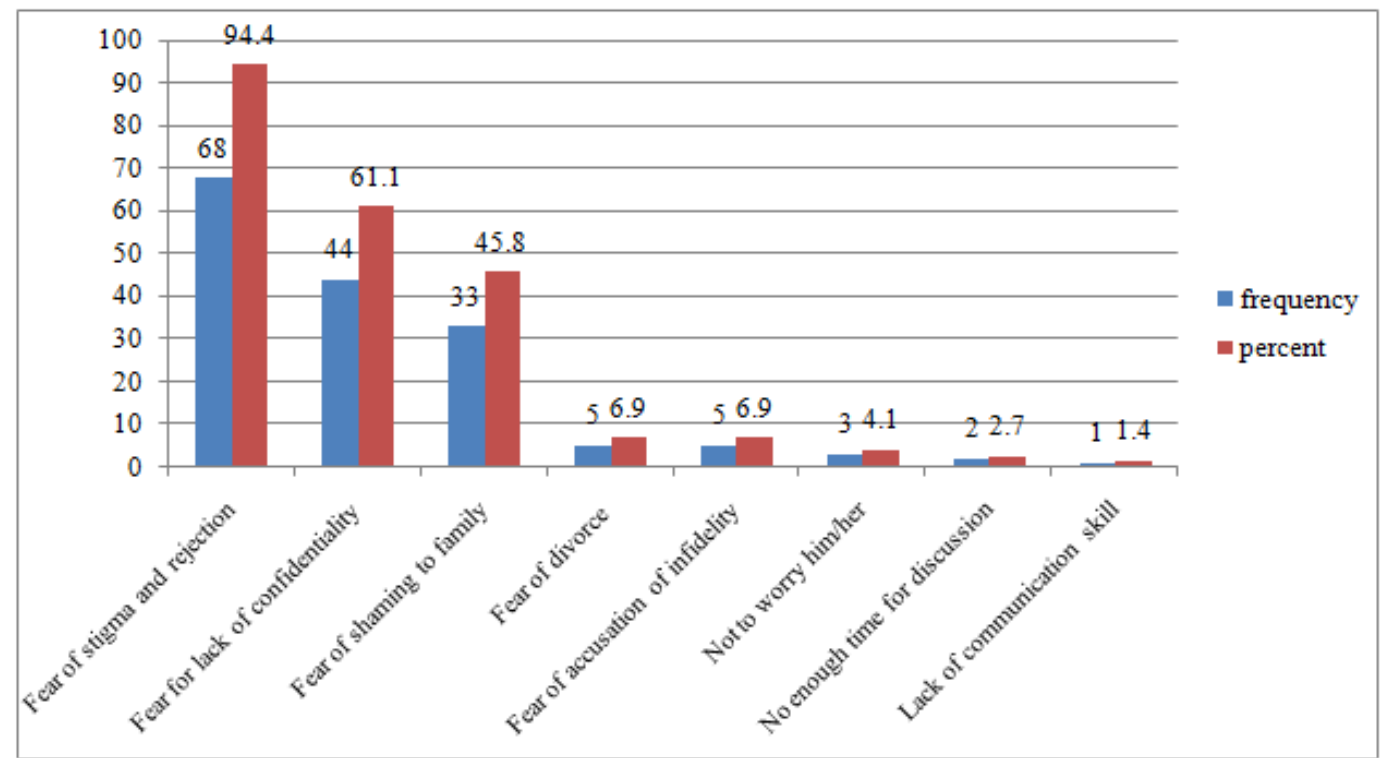

Figure 2. Reasons not to disclose HIV positive results to partner/parentffamilies among HIV positive adults in Axum health facilities, Tigray, Ethiopia 2013.

\section{Determinant of HIV Positive Status Disclosure}

On bivariate analysis marital status of respondents, type of sexual partner, ART started, educational status of sexual partner, knowledge of partner's HIV status, sexual partner's HIV status, discussion about HIV/AIDS prior test, being membership of Anti- HIV association and use of condom were significantly associated with HIV positive status disclosure [Table 3].

After adjusting variables in the multivariate logistic regression analysis variables significant at $p$-value $<0.05$ were; marital status of respondents, knowledge of the partner's HIV status and membership of Anti- HIV/AIDS association.

Unmarried respondents were 3.7 times more likely to disclose to their HIV positive status as compared to married $(\mathrm{AOR}=3.70 ; 95 \% \mathrm{CI}, 1.206-11.39)$. Respondents who knew their sexual partner's HIV status were 3.4 times more likely to disclose their HIV positive status as compared to those who did not know their partner's HIV status $(\mathrm{AOR}=3.43$; 95\% CI, 1.02- 11.5). Participants who are members of Anti- AIDS association were 4.8 times more likely disclose their HIV positive result as compared to those not a member of AntiAIDS association. (AOR $=4.81 ; 95 \% \mathrm{CI}, 1.01-23.05)$.

Table 3. Factors independently associated with HIV-positive result disclosure among HIV-positive adults, Axum health facilities, Tigray, Ethiopia, 2013.

\begin{tabular}{|c|c|c|c|c|c|}
\hline \multirow{2}{*}{ Variables } & \multirow{2}{*}{ Categories } & \multicolumn{2}{|c|}{ Disclosure status } & \multirow{2}{*}{$\operatorname{COR}(95 \%, \mathrm{CI})$} & \multirow{2}{*}{$\operatorname{AOR}(95 \%, C I)$} \\
\hline & & Yes & No & & \\
\hline \multirow{2}{*}{$\begin{array}{l}\text { Marital status of } \\
\text { respondents }\end{array}$} & Unmarried & 235 & 44 & $2.77(1.58-4.84)$ & $3.71(1.21-11.39) * *$ \\
\hline & Married & 54 & 28 & 1.00 & 1.00 \\
\hline \multirow{2}{*}{ Use of condom } & Yes & 143 & 15 & $3.72(2.02-6.88)$ & $0.40(0.062-2.60)$ \\
\hline & No & 146 & 57 & 1.00 & 1.00 \\
\hline \multirow{2}{*}{ ART started } & Yes & 270 & 61 & $2.56(1.16-5.66)$ & $2.81(0.587-13.42)$ \\
\hline & No & 19 & 11 & 1.00 & 1.00 \\
\hline \multirow{2}{*}{$\begin{array}{l}\text { Discussion about HIV } \\
\text { before test }\end{array}$} & Yes & 76 & 6 & $3.93(1.64-9.42)$ & $1.42(0.38-5.33)$ \\
\hline & No & 213 & 66 & 1.00 & 1.00 \\
\hline \multirow{2}{*}{ Types of partnership } & Regular sexual partner & 128 & 9 & $2.77(1.01-7.66)$ & $0.92(0.13-6.62)$ \\
\hline & Non regular sexual partner & 41 & 8 & 1.00 & 1.00 \\
\hline \multirow{2}{*}{$\begin{array}{l}\text { Knowledge of partner's } \\
\text { HIV status }\end{array}$} & Yes & 152 & 11 & $4.87(1.60-14.85)$ & $3.43(1.021-11.54)^{* *}$ \\
\hline & No & 17 & 6 & 1.00 & 1.00 \\
\hline \multirow{2}{*}{$\begin{array}{l}\text { Sexual Partner's HIV } \\
\text { status }\end{array}$} & Positive & 125 & 8 & $3.2(1.16-8.796)$ & $1.31(0.297-5.77)$ \\
\hline & Negative & 44 & 9 & 1.00 & 1.00 \\
\hline \multirow{2}{*}{$\begin{array}{l}\text { Membership of HIV } \\
\text { association }\end{array}$} & Yes & 109 & 7 & $5.62(2.49-12.71)$ & $4.81(1.004-23.05)^{* *}$ \\
\hline & No & 180 & 65 & 1.00 & 1.00 \\
\hline
\end{tabular}

** Variables significantly associated at $\mathrm{P}<0.05$ 


\section{Discussion}

Disclosure of HIV positive result enables individual to practice safer sex to make informed options preventions that may ultimately lower the number of newly infected, and even to reduce the risk of HIV transmission from mother to child and to take medications properly.

It also prevents HIV infection of the sexual partner with a discordant sero-status. For instance $30(16.1 \%)$ of the respondents in this study their sexual partners were HIV negative.

In this study, the rate of HIV positive status disclosure to at least one person is $80.1 \%$. The finding is lower than the study done in Hawasa referral hospital, Ethiopia which is $92.2 \%$, in Jimma University referral hospital, Ethiopia, which is $94.5 \%$ and in kemissie district, north east Ethiopia that is $93.1 \%$ of the respondents disclose their HIV positive status [7, 8, 11].

The reason could be the study subjects from Jimma and Hawasa University Hospitals might get adequate HIV related information easily than Axum health facilities as they are teaching hospitals which are equipped with skilled man power. Besides to this, it might be also due to socio demographic characteristics difference between the study subjects.

Seventy two (19.9\%) of the respondents did not disclose their HIV positive status to anyone.

Some of the reasons for non disclosure in this study were fear of stigma and rejection, fear of breach of confidentiality, fear of shaming to families/ parents, and fear of divorce; which is consistent with the studies carried out elsewhere in Ethiopia $[6,8,11]$. These reasons are also similar to studies done in different developing countries like Uganda, South Africa, Tanzania and Djibouti [10, 15, 17, 24].

Concerning disclosure to one's sexual partner, this study confirms that most participants have disclosed their HIV positive status to their sexual partner (81.2\%): only $18.8 \%$ of the HIV positive adults who have sexual partner did not disclose their HIV status to their sexual partner. This report is higher than figures reported in Kemissie (6.9\%) [8], and (7.6\%) and Jimma (9.8\%) [7], and slightly lower than studies from Wolidia (23.3\%) [6] and South Africa (21\%) [18].

In multivariate analysis, it was observed that marital status of the respondents, knowledge of partners HIV status and membership of anti- HIV/AIDS association were independently associated with disclosure of HIV positive Status.

Unmarried respondents were more likely to disclose their HIV positive status compared to married one (AOR $=3.706$, $95 \%$ CI, $1.206-11.388$ ). This finding is contrary with other studies done in Hawasa [9]. This might be due to the fact that married individuals have fear of being blamed of one over another on who first acquired the infection and may lead to disagreement and divorce of couples. As a result they prefer not to disclose their HIV positive status than the outcome consequences.

Knowledge of partner's HIV status was found to be a predictor of HIV positive status disclosure; which is 3.43 times more likely to disclose their HIV status as compared to those who did not know their partner's HIV status.(AOR = 3.43 , 95\% CI $1.02-11.5)$. This agrees with what others reported $[8,11]$. Majority of the respondents $(81.6 \%)$ had similar HIV positive status with partner. This might help them to have open communication and freedom to disclose.

Respondents who were a member of Anti- HIV/AIDS association were more likely to disclose their HIV status as compared to counterpart. (AOR $=4.81,95 \% \mathrm{CI}, 1.01$ 23.05). The finding is in line with the study done in kemissie [8]. This could be individuals who were a member has frequent discussion related to HIV and they feel first to bring behavioral changes.

\section{Conclusions}

The rate of HIV positive status disclosure among HIV positive adults still continued to be low. Reasons for nondisclosure among those respondents who did not disclose their HIV positive status to their partner/parents/families were; fear of stigma and rejection, fear of breach of confidentiality, fear of shaming to family, fear of divorce (separation) and fear of accusation of infidelity. Marital status of respondents, knowledge of partners HIV status, and member of Anti- AIDS association were identified as predictors of HIV positive status disclosure.

Adherence and disclosure counselors should give stress to married couples counseling to disclose their HIV positive status to think their partner's health status. Anti- HIV/AIDS associations and supporting group associations should be strengthen and get support in material and moral to be sustainable in their work.

\section{Acknowledgments}

We would like to thank Bahir dar University for funding this research. Our gratitude goes to supervisors, data collectors and respondents who participated on this study.

\section{Authors' Contributions}

HB, WA, MB and MG designed the study, analyzed the data, drafted the manuscript and critically reviewed the article. All authors read and approved the final manuscript.

\section{References}

[1] Global report, UNAIDS Report on the global AIDS epidemic | 2012. Available at www.unaids.org

[2] Federal democratic republic of Ethiopia, Ministry of Health, health sector development programme IV, annual performance report EFY 2003(2010/11) version.

[3] WHO Document Summary (2004). HIV Status Disclosure to Sexual Partners: Rates, Barriers and Outcomes for Women, Rates of HIV status disclosure, available from http://www.who.int/gender/en. 
[4] Naaman N. Kajura and Nikki Schaay, "The perceived and experienced barriers and reported consequences of HIV positive status disclosure by people living with HIV to their partners and family members in Djibouti," masters mini thesis 2010. Unpublished.

[5] WHO, UNAIDS, Guidance on encouraging beneficial disclosure, ethical partner counseling and appropriate use of HIV case reporting 2000.

[6] Tadese A., Berihun M., Mamo W. "Predictors of HIV status disclosure to sexual partners among People living with HIV/AIDS in Ethiopia," Pan African Medical Journal, 2012; 13(87).

[7] K. Deribe, K. Woldemichael, M. Wondafrash, A. Haile, and A. Amberbir, "Disclosure experience and associated factors among HIV positive men and women clinical service users in southwest Ethiopia,” BMC Public Health, 2008, 8:81

[8] S. Mohammed, W. Belaynew, and A. Mengesha, "Disclosure of HIV Positive Result to a Sexual Partner among Adult Clinical Service Users in Kemissie District, Northeast Ethiopia,” Afr J Reprod Health, 2012; 16(1): pp.97-104.

[9] D. Kebede, L. Wassie, and D. Yismaw, "Determinants and outcomes of disclosing HIV- sero positive status to sexual partners among women in Mettu and Gore towns, Illubabor Zone southwest Ethiopia,” Ethiop.J.Health Dev., 2005; 19(2): pp.126-131.

[10] G. Antelman et al, "Associated factors of HIV-1 status disclosure: A prospective study among HIV-infected pregnant women in Dar es Salaam, Tanzania," AIDS 2001, Vol 15, pp. 1865-1874.

[11] Taye Gari, Dereje Habte,and Endrias Markos, "HIV positive status disclosure to sexual partner among women attending ART clinic at Hawassa University Referral Hospital," SNNPR, Ethiopia. Ethiop. J. Health Dev.2010;24(1):pp. 9-14

[12] Geneviève Rouleau, José Côté, and Chantal Cara, "Disclosure experience in a convenience sample of quebec-born women living with HIV," a phenomenological study, BMC Women's Health, 2012, 12:37

[13] Rapid response service; Disclosure of HIV-positive status: Towards the development of guidelines, strategies and interventions rapid service \# 65 march 2013

[14] Philip Anglewicza,and Jesman Chintsanya, "Disclosure of HIV Status between Spouses in Rural Malawi," BMC AIDS Care, 2011 August; 23(8): pp. 998-1005.
[15] Isaac Kadowa, and Fred Nuwaha, "Factors influencing disclosure of HIV positive status in Mityana district of Uganda," African Health Sciences, 2009; 9(1):pp.26-33

[16] Pride Mucheto et al., "Determinants of nondisclosure of HIV status among women attending the prevention of mother to child transmission programme, Makonde district, Zimbabwe," Pan Africa journal, 2011; 8:51.

[17] Jennifer D.Makin et al., "Factors Affecting Disclosure in South African HIV-Positive Pregnant Women," AIDS Patient Care and STDs, 2008, Volume 22, Number 11

[18] L.C. Simbayi, S.C.Kalichman, A.Strebel, A. Cloete, N. Henda, and A. Mqeketo, "Disclosure of HIV status to sex partners and sexual risk behaviours among HIV-positive men and women, Cape Town, South Africa," Sex Transm Infect.,2007 Feb;83(1):pp. 29-34.

[19] WHO: Gender Dimensions of HIV status Discourse to sexual partners. Rates, Barriers \& outcomes: A Review paper. WHO. Geneva, Switzerland; 2004.

[20] Serovich Jm, and Mosack XE, "Reasons for HIV disclosure or non-disclosure to causal sexual partners," SIDS Educ prev., 2003; 15: pp. 70-80.

[21] Michael Legasion, and G. A. Ogunbanjo, "A study on Factors associated with non-disclosure of HIV positive status to sexual partners by adult patients attending the VCT clinic at Nhlangano health centre, Swaziland," Masters dissertation, 2012.unpublished

[22] Axum Woreda health office, 2012 annual performance report. Unpublished document from the District Health Office.

[23] AIDS IN ETHIOPIA, Federal Ministry of health/ National HIV/AIDS prevention and control (FHAPCO), Sixth report.

[24] Ngozi C. Mbonu, Bart Van Den Borne, and Nanne K. De Vries. "Societal beliefs and reactions about people living with HIV/AIDS," InTech, 2011, www.intechopen.com

[25] A. Medley, C. Gacial -Moron, S, McGill, and S. Maman, "Rates Barriers and Outcomes of HIV Sero - status Disclosure among Women in Developing Countries: Implication for Prevention of Mother to Child Transmission Programmes," Bulletin of the World Health Organization 2004, 82: pp. 299307 